\title{
PHARMACOKINETIC STUDIES OF A CHRONOTHERAPEUTIC DRUG DELIVERY SYSTEM OF LORNOXICAM BY LC-MS/MS METHOD
}

\author{
SINDHU ABRAHAM ${ }^{1 *}$, RAJAMANICKAM DEVESWARAN ${ }^{1}$, JAYARAMAN ANBU ${ }^{2}$, SHARON FURTADO ${ }^{1}$, SRINIVASAN \\ BHARATH $^{1}$
}

\author{
1Department of Pharmaceutics, Faculty of Pharmacy, ${ }^{2}$ Department of Pharmacology, Faculty of Pharmacy, M. S. Ramaiah University of \\ Applied Sciences, Gnanagangothri Campus, MSR Nagar, Bengaluru 560054 \\ Email: sindhu.ps.ph@msruas.ac.in \\ Received: 21 May 2018, Revised and Accepted: 04 Sep 2018
}

\section{ABSTRACT}

Objective: The objective of this study was to investigate differences in pharmacokinetic patterns of immediate release tablet (IR) and compression coated tablet (CCT) of lornoxicam, proposed for the chronotherapeutic treatment of rheumatoid arthritis.

Methods: The dosage forms were administered to two groups of white New Zealand rabbits ( $\mathrm{n}=3$ ), and the plasma drug levels were measured by liquid chromatography-tandem mass spectrometry (LC-MS/MS). Pharmacokinetic parameters like maximum concentration (Cmax), time is taken to reach maximum concentration (Tmax), area under the curve (AUC), elimination half-life $\left(\mathrm{t}_{1 / 2}\right)$ and Mean Residence Time (MRT) were determined.

Results: In the case of IR tablets, the drug was detected within $15 \mathrm{~min}$ after oral administration and a Cmax of $1269.57 \pm 4.04 \mathrm{ng} / \mathrm{ml}$ were attained at $2 \pm 0.15 \mathrm{~h}$. With CCT, the drug was detected only after $5 \mathrm{~h}$ and a Cmax of $1279.24 \pm 12.76 \mathrm{ng} / \mathrm{ml}$ were attained at $8 \pm 0.10 \mathrm{~h}$. The CCT showed maximum drug release at the eighth hour in comparison to IR tablet which showed maximum release at the second hour of study.

Conclusion: The predominant lag time prior to drug release from CCT is an indication that it is consistent with the requirements of chronopharmaceutical drug delivery. The results suggest that the compression coated tablet is a promising approach for chronotherapeutic management of rheumatoid arthritis.

Keywords: lornoxicam, Chronotherapeutic, LC-MS/MS, Pharmacokinetic studies, New zealand rabbits

(C) 2018 The Authors. Published by Innovare Academic Sciences Pvt Ltd. This is an open access article under the CC BY license (http://creativecommons.org/licenses/by/4.0/) DOI: http://dx.doi.org/10.22159/ijap.2018v10i6.27453

\section{INTRODUCTION}

Chronotherapeutics refers to a treatment method that is in accordance with a patient's daily, monthly, seasonal or yearly biological clock, in order to achieve maximum therapeutic benefits and minimal adverse effects. Chronotherapeutic drug delivery systems (ChrDDs) with a preset lag time are helpful for patients suffering from allergic rhinitis, rheumatoid arthritis (RA) and related disorders, asthma, cancer, cardiovascular diseases and peptic ulcer disease as the drug is released at a predetermined time and the maximum concentration $\left(\mathrm{C}_{\max }\right)$ of the drug will be reached when the symptoms of the disease are at its peak [1-3].

Rheumatoid arthritis (RA) is a chronic, autoimmune inflammatory disease characterized by joint swelling, tenderness and progressive destruction of synovial joints, leading to severe disability and premature mortality [4]. Morning stiffness that lasts for hours in one or more of the smaller joints is a common early sign of RA. Chronopharmacotherapy for RA has been recommended to ensure that the highest blood levels of the drug coincide with the incidence of pain and stiffness. Compression coated tablets (CCT) are dosage forms consisting of an inner immediate release core tablet embedded in an outer layer made of a hydrophilic or hydrophobic polymer or a combination of both. The outer layer disintegrates or dissolves slowly to release the drug after a predetermined lag time $[5,6]$.

This technique is simple, economical and eliminates the need for a tedious and time-consuming granulation or coating processes. It can be used to physically separate two incompatible drugs within the same dosage form and also improves the stability of the drug by protecting it from moisture [7]. Current drugs that are available in the market are conventional film-coated, and enteric coated tablets of NSAIDs and these dosage forms are to be taken twice or thrice a day post meals. This does not reduce the pain and stiffness of RA patients, especially in the early morning hours. This necessitates the present study on the development of compression coated tablets and to study differences in the pharmacokinetic patterns of a compression coated tablet and an immediate release tablet (conventional), both containing the same dose of lornoxicam.

\section{MATERIALS AND METHODS}

\section{Materials}

Lornoxicam was a generous gift sample from Lifecare formulations, Puducherry, India. Ethyl acetate-AR grade, methanol-HPLC grade, and Milli-Q water-HPLC grade were procured from SD fine chemicals ltd, India.

The study protocols were approved by the institutional animal ethics committee (IAEC) of M. S Ramaiah College of Pharmacy, Bangalore, India (CPCSEA approval no: 220/PO/abc/2000/CPCSEA and renewal approval no: XVIII/MSRFPH/P-10/8.2.17)

\section{Methods}

\section{a) Dosage forms}

Immediate release core tablets containing $8 \mathrm{mg}$ lornoxicam and compression coated with an interpenetrating polymer network (IPN) of chitosan-poly (acrylamide) were chosen as dosage forms for the study.

\section{b) Animals}

The pharmacokinetic study [8] was performed using New Zealand white rabbits $(2.5-3 \mathrm{~kg})$ of either sex. The animals were housed in polycarbonate cages in a room maintained under constant environmental conditions $\left(22 \pm 1{ }^{\circ} \mathrm{C}, 50 \pm 5 \% \mathrm{RH}\right)$. Food and water were given ad libitum. Six rabbits were divided into two groups (A and $\mathrm{B}$ ); containing three rabbits each. The numbers of animals were selected as per the recommendations of the IAEC. Group, I rabbits was administered immediate release core tablets (IR) of lornoxicam, and group II rabbits were administered compression coated tablets (CCT) of lornoxicam [9-13]. 
The study was conducted in a crossover design with a washout period of three weeks in between the two experiments. The dosage forms were administered using sterile internal stomach pumps.

\section{c) Dose fixation}

The human dose of lornoxicam is $8 \mathrm{mg}$ and the dose given to each rabbit was adjusted to $0.4 \mathrm{mg} / \mathrm{kg}$ according to Paget and Barnes [14].

\section{d) Blood sampling}

The rabbits were fasted overnight for $12 \mathrm{~h}$ prior to the study. The tablet was administered using sterile feeding tubes. The animals were fed $4 \mathrm{~h}$ after drug dosing and had free access to water throughout the study period. $2 \mathrm{ml}$ of blood samples were collected through the marginal ear vein into heparinized tubes at predetermined intervals of $0,15,30,60,120,240,360,480$ and 600 min postdose. The plasma was separated immediately by centrifugation at $10000 \mathrm{rpm}$ for $5 \mathrm{~min}$ and maintained at $-20^{\circ} \mathrm{C}$ until further analysis.

\section{e) Analytical method development for determination of lornoxicam in rabbit plasma}

Drug levels in the plasma were analyzed by LC-MS/MS [8].

\section{Preparation of lornoxicam standard stock solution}

$10 \mathrm{mg}$ of accurately weighed lornoxicam working standard was transferred into a $10 \mathrm{ml}$ volumetric flask, dissolved in methanol and the volume was made with methanol to produce a stock solution of strength $1000 \mu \mathrm{g} / \mathrm{ml}$. This solution was stored in a refrigerator at 2$8{ }^{\circ} \mathrm{C}$. Working internal standard solutions in the concentration range $5.0-2200.00 \mathrm{ng} / \mathrm{ml}$ were prepared by suitably diluting the stock solution with methanol afresh before use.

\section{Spiking of blank plasma samples}

$180 \mu \mathrm{l}$ of drug-free rabbit plasma was spiked with $20 \mu \mathrm{l}$ of lornoxicam standard calibrants $(5.0-2137.45 \mathrm{ng} / \mathrm{ml})$, separately extracted with $800 \mu \mathrm{l}$ ethyl acetate and analyzed by LC-MS. The response obtained for different levels of calibrants was analyzed by linear regression and regression equation obtained was used for estimating lornoxicam concentration in unknown rabbit plasma samples processed similarly.

Regression equation used for calculating lornoxicam in unknown samples:

\section{$\mathrm{Y}=54.436 \mathrm{X}+888.54$,}

Where $Y=$ peak area of lornoxicam, and

$\mathrm{X}$ is the concentration of lornoxicam in $\mathrm{ng} / \mathrm{ml}$ of plasma samples.

\section{Preparation of plasma samples}

All the frozen rabbit plasma samples were thawed at room temperature and vortexed to ensure uniform mixing of contents.
Lornoxicam was selectively isolated from $200 \mu \mathrm{l}$ plasma by liquidliquid extraction using ethyl acetate as the extraction solvent. $200 \mu \mathrm{l}$ plasma was vortexed with $800 \mu \mathrm{l}$ ethyl acetate for $5 \mathrm{~min}$ at 2500 $\mathrm{rpm}$. The mixture was centrifuged at $12000 \mathrm{rpm}$ for $5 \mathrm{~min}$ and the supernatant collected. The extract was then evaporated to dryness under a stream of nitrogen followed by reconstitution with $100 \mu \mathrm{l}$ of mobile phase (acetonitrile: $2 \mathrm{mmol}$ ammonium formate buffer in the ratio $70: 30 \mathrm{v} / \mathrm{v}$ ). $10 \mu \mathrm{l}$ of the prepared sample was then injected into the LC-MS/MS system and analyzed for drug content.

\section{Instrumentation and chromatographic conditions}

Shimadzu PROMINENCE LC-20AT series HPLC was used. The equipment consisted of an AGILENT ZORBAX XB-C18 column $(5 \mu \mathrm{m}$ particle size; $50 \mathrm{~mm} * 4.6 \mathrm{I}$. D). The mobile phase used was acetonitrile: $2 \mathrm{mmol}$ ammonium formate buffer $(70: 30 \mathrm{v} / \mathrm{v})$ and was run at a flow rate of $0.4 \mathrm{ml} / \mathrm{min}$. The temperature of the column oven was maintained at $45{ }^{\circ} \mathrm{C}$ and that of the autosampler at $10{ }^{\circ} \mathrm{C}$. The injection volume was $10 \mu \mathrm{l}$ and the total run time was $10 \mathrm{~min}$.

LC-MS/MS analysis was performed on SCIEX series API 4000 triple, quadruple mass spectrometer equipped with electrospray ionization (ESI) interface with turbo ion spray. Positive ions were measured in mode (ionspray voltage: $5300 \mathrm{KV}$, declustering potential: $86.50 \mathrm{eV}$, entrance potential: $12.50 \mathrm{eV}$, temperature of source: $450{ }^{\circ} \mathrm{C}$ ). The mass spectrometer was programmed to monitor the precursor ion $[\mathrm{M}+\mathrm{H}]$ of lornoxicam at $\mathrm{m} / \mathrm{z} 372$ and fragment ion $[\mathrm{M}+\mathrm{H}]+$ at $\mathrm{m} / \mathrm{z}$ 121.60

\section{f) Data analysis}

Pharmacokinetic parameters like maximum concentration (Cmax), time taken to reach maximum concentration (Tmax), area under the curve $\left(\mathrm{AUC}_{0-24}\right)$, area under the first moment curve $\left(\mathrm{AUMC}_{0-24}\right)$, elimination half-life $\left(t_{1 / 2}\right)$ and mean residence time (MRT) were determined by Kinetica 5.0 (Thermofisher Scientific, PK/PD software, USA) for each sample.

\section{RESULTS AND DISCUSSION}

The primary goal for developing any dosage form is to deliver the required concentration of an active drug substance to the site of action and to achieve optimum efficacy. The ability of compression coated tablets as a drug delivery system to release drugs in a predetermined time-release manner was investigated in New Zealand white rabbits. The core and compression coated tablets of lornoxicam, prepared and evaluated under laboratory conditions were considered for pharmacokinetic studies.

A rapid and selective analytical method was developed for the quantitative analysis of lornoxicam in rabbit plasma. A retention and separation of lornoxicam were obtained by using acetonitrile: 2 mmol ammonium formate buffer $(70: 30 \mathrm{v} / \mathrm{v})$ as the mobile phase. The correlation coefficient for lornoxicam over the concentration range of $5.0 \mathrm{ng} / \mathrm{ml}-2137.45 \mathrm{ng} / \mathrm{ml}$ was found to be 0.9984 . The average slope and intercept of regression equations were 54.43 and 888.5 respectively (table 1 and fig. 1 ).

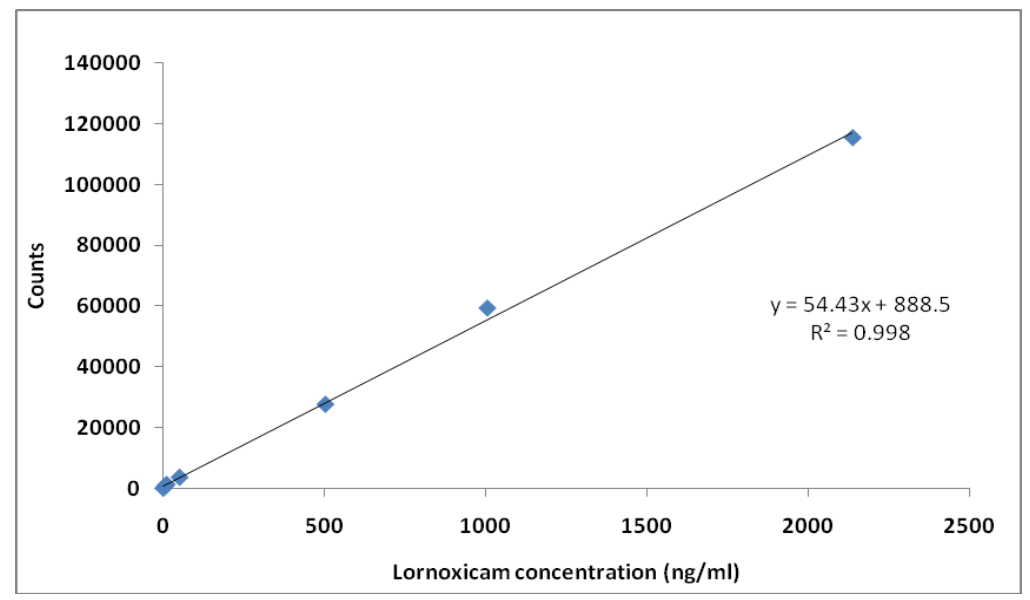

Fig. 1: The calibration curve of lornoxicam in rabbit plasma 
Table 1: Data for standard calibration curve of lornoxicam in rabbit plasma

\begin{tabular}{ll}
\hline Concentration $(\mathbf{n g} / \mathbf{m l})$ & Counts $\mathbf{S D}$ (peak area)* $^{*}$ \\
\hline 5.00 & $683.00 \pm 1.15$ \\
10.05 & $1232.00 \pm 0.577$ \\
50.23 & $3601.00 \pm 1.52$ \\
502.30 & $27666.00 \pm 0.577$ \\
1004.60 & $59396.00 \pm 1.00$ \\
2137.45 & $115583.00 \pm 0.577$ \\
\hline
\end{tabular}

*Each value is represented as a mean \pm standard deviation of three observations $(n=3)$

The LC-MS/MS method was found to satisfy the requirement of routine analyses as it had a short run time (3 min). The MS optimization was performed by direct injection of lornoxicam into the mass spectrometer. The mass parameters were optimized to obtain better ionization of lornoxicam molecules. The full scan spectrum [15] was dominated by protonated molecule $\mathrm{m} / \mathrm{z} 372.00$ for lornoxicam and the major fragment ions observed in the product spectrum was at m/z 121.60 (fig. 2-3)

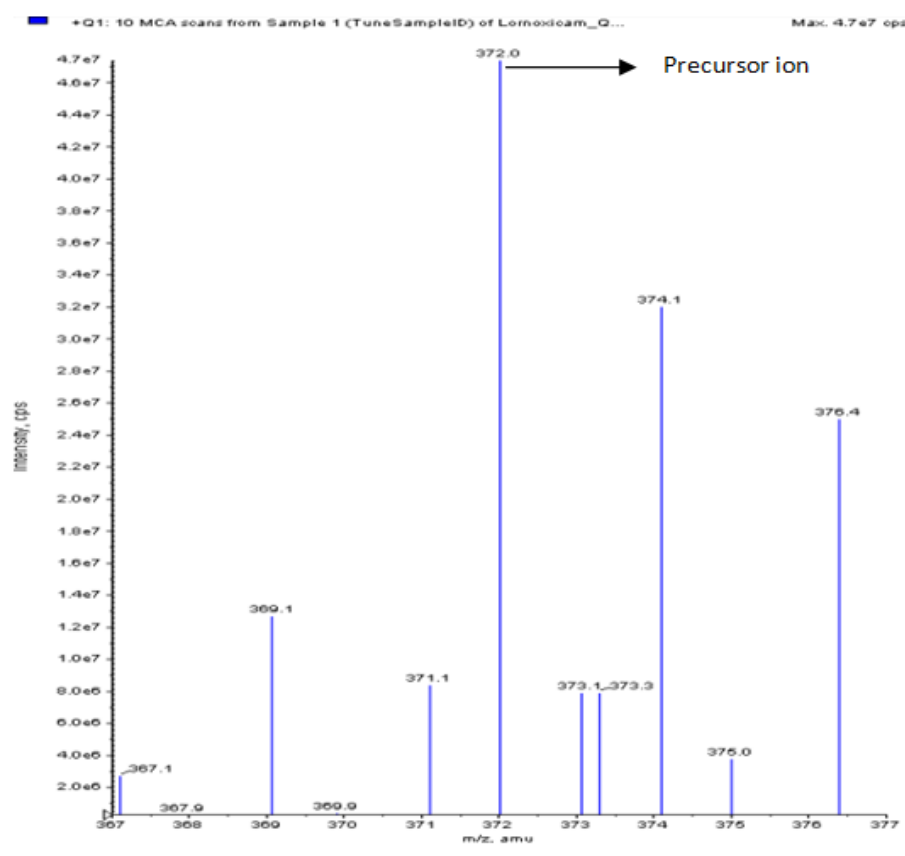

Fig. 2: Mass scan of lornoxicam standard

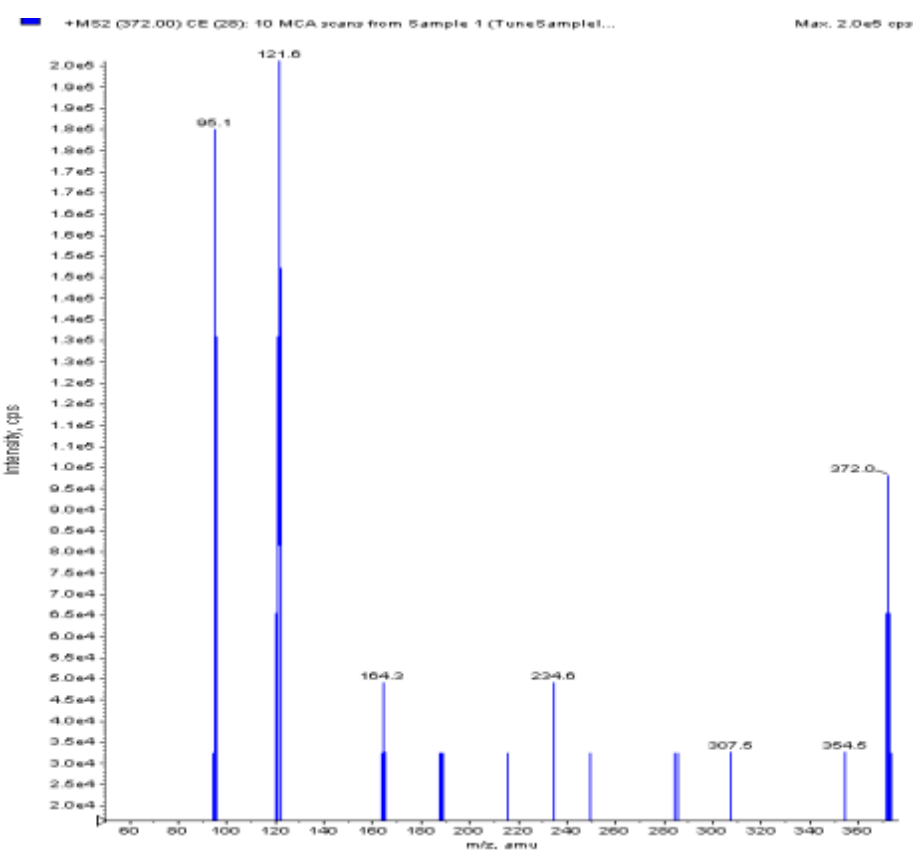

Fig. 3: Product ion spectrum of lornoxicam standard 


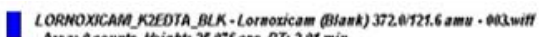

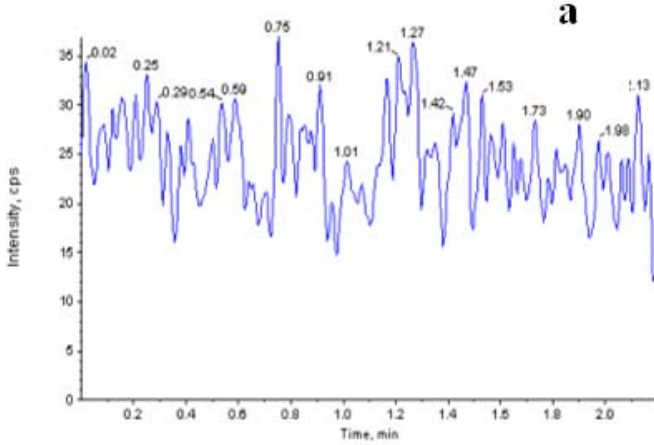

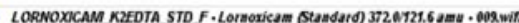

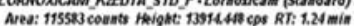

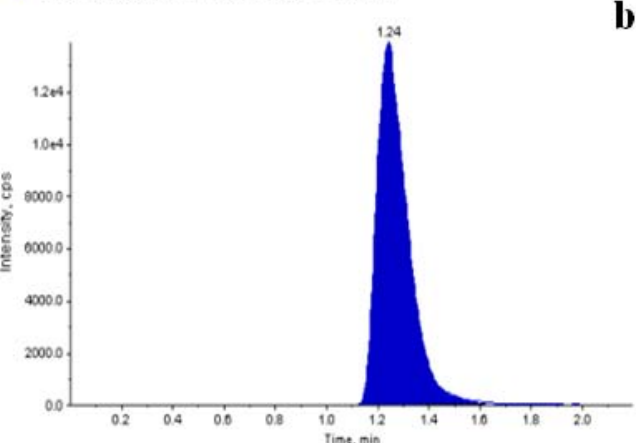

Fig. 4: Single ion monitoring (SIM) chromatogram of a) blank plasma sample and b) lornoxicam standard (concentration-2137.45 ng/ml)

The retention time obtained for lornoxicam was $1.24 \mathrm{~min}$. The representative chromatograms of blank plasma and plasma samples spiked with lornoxicam are shown in fig. 4.

The developed LC-MS/MS method was successfully applied for pharmacokinetic study in rabbits. In the case of IR, the drug was detected within 15 min after its oral administration in rabbits. The chromatograms of plasma samples withdrawn at different intervals of time for IR are shown in fig. 5.
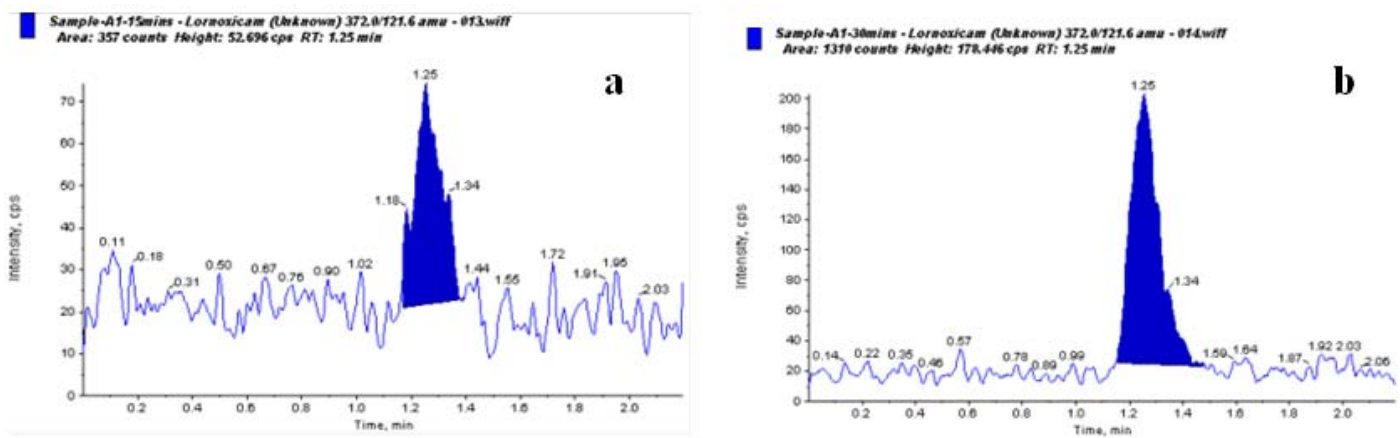

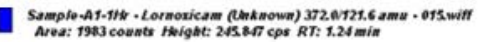
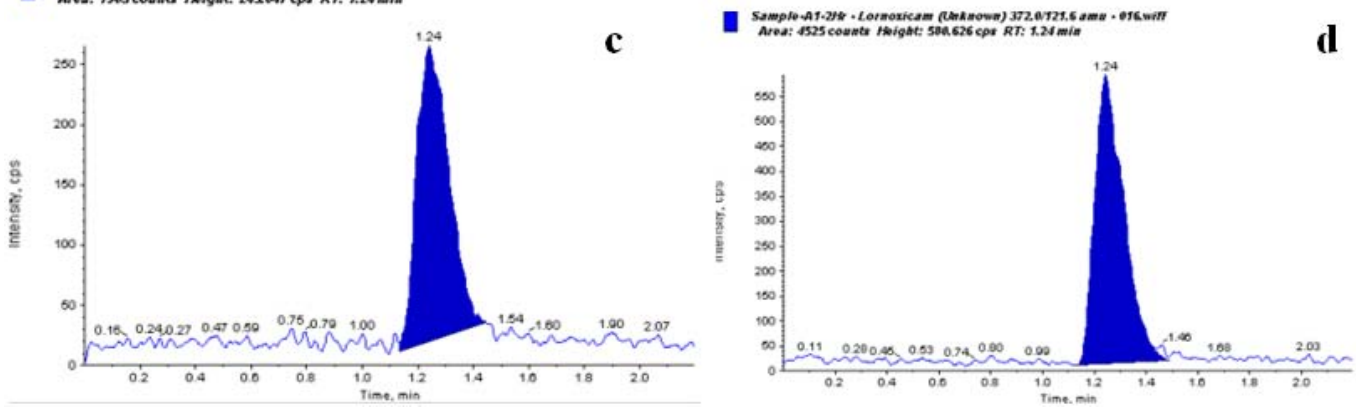

Fig. 5: LC-MS chromatogram of IR-a) at $15 \mathrm{~min} \mathrm{b)} 30 \mathrm{~min} \mathrm{c)} 1 \mathrm{~h} \mathrm{d)} 2 \mathrm{~h}$

In the case of CCT, the drug was detected only after $5 \mathrm{~h}$. This indicates that there was a predominant lag time before the drug release. The chromatograms of plasma samples withdrawn at different intervals of time for CCT are shown in fig. 6 [16].

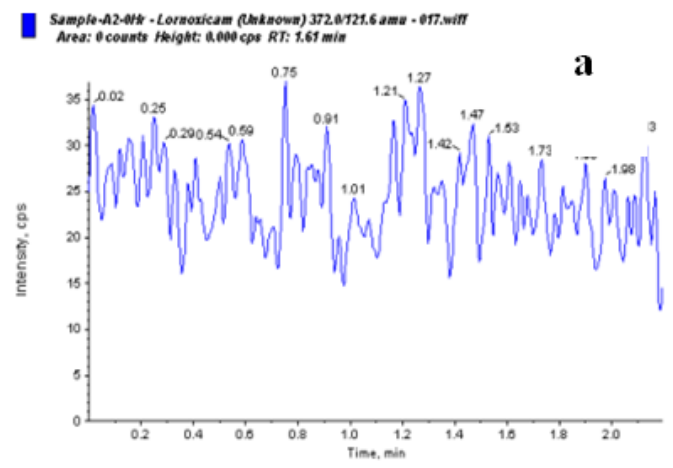

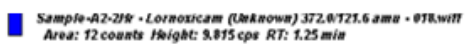

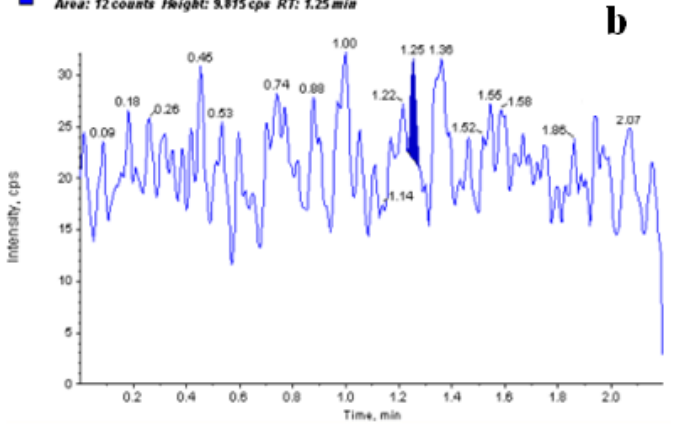



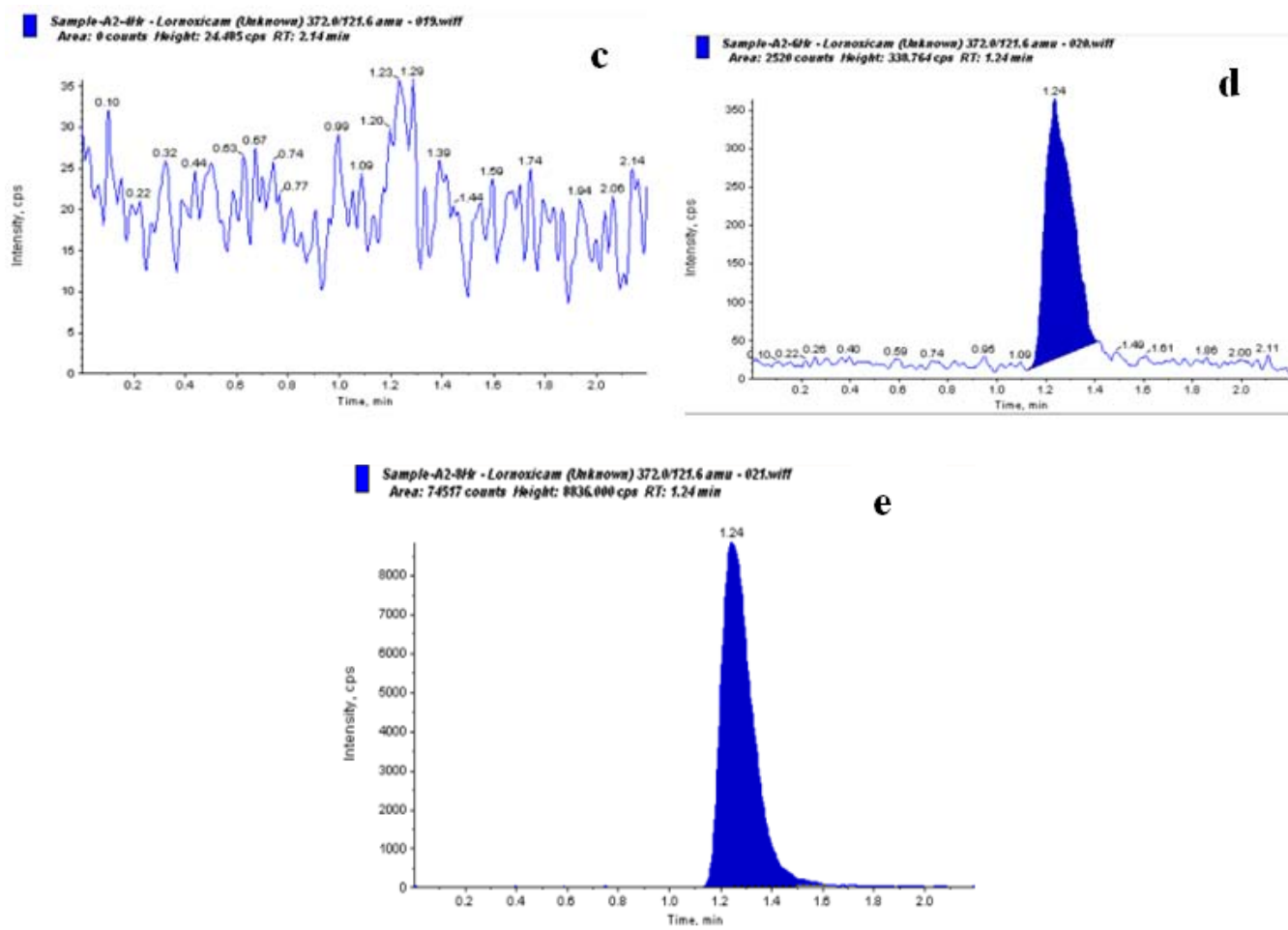

Fig. 6: LC-MS chromatogram of (CT-a) at $0 \mathrm{~h} \mathrm{b)} 2 \mathrm{~h} \mathrm{c)} 4 \mathrm{~h} \mathrm{d)} 6 \mathrm{~h} \mathrm{e)} 8 \mathrm{~h}$

The drug absorption was rapid in the case of IR, i.e., a Cmax of $1269.57 \pm 4.04 \mathrm{ng} / \mathrm{ml}$ was attained at a Tmax of $2 \pm 0.15 \mathrm{~h}(120$ min) h. In CCT, a Cmax of $1279.24 \pm 12.76 \mathrm{ng} / \mathrm{ml}$ was attained at a Tmax of $8 \pm 0.10 \mathrm{~h}(480 \mathrm{~min})$, but no drug was detected till $5 \mathrm{~h}$ in all the three rabbits, indicating a similar correlation with in vitro release. The $\mathrm{AUC}_{0-24}$ for animals administered IR was found to be $4503.59 \pm 42.0 \mathrm{ng} / \mathrm{ml} \mathrm{h}$ and $4598.36 \pm 74.1 \mathrm{ng} / \mathrm{ml} \mathrm{h}$ for animals administered CCT.
MRT is defined as the average time spent by the drug in the body and can be used to compare the in vivo performance of different dosage forms. The difference in MRT values 3.45 and $9.12 \mathrm{~h}$ for IR and CCT respectively) is an indication of the pulsatile release pattern of compression coated tablet. The other pharmacokinetic parameters [9] determined were $\mathrm{AUMC}_{0-24}, \mathrm{t} 1 / 2$ and Ke (table 2 and fig. 7). The results of the in vivo studies indicated that drug release from CCT took place only after the desired lag time.

Table 2: Summary of pharmacokinetic parameters of all the groups

\begin{tabular}{lll}
\hline Pharmacokinetic parameters & Group I (Core tablets of lornoxicam)* & Group II (Compression coated tablets of lornoxicam)* \\
\hline$C_{\max }(\mathrm{ng} / \mathrm{ml})$ & $1269.57 \pm 12.89$ & $1279.24 \pm 12.76$ \\
Tmax $(\mathrm{h})$ & $2 \pm 0.15$ & $8 \pm 0.10$ \\
Lag time $(\mathrm{h})_{\mathrm{AUC}_{0-24}(\mathrm{ng} / \mathrm{mlh})}$ & $0 \pm 0$ & $5 \pm 0.10$ \\
$\mathrm{AUMC}_{0-24}\left(\mathrm{ng} / \mathrm{ml}^{*}[\mathrm{~h}]^{2}\right)$ & $4503.59 \pm 42.0$ & $4598.36 \pm 74.1$ \\
$\mathrm{t}_{1 / 2}(\mathrm{~h})$ & $15552.4 \pm 261.92$ & $41968.23 \pm 808.25$ \\
Ke $\left(\mathrm{h}^{-1}\right)$ & $1.43 \pm 0.01$ & $1.53 \pm 0.025$ \\
MRT $(\mathrm{h})$ & $0.48 \pm 0.005$ & $0.45 \pm 0.005$ \\
\hline
\end{tabular}

* Each value is represented as a mean \pm standard deviation of three observations $(n=3)$

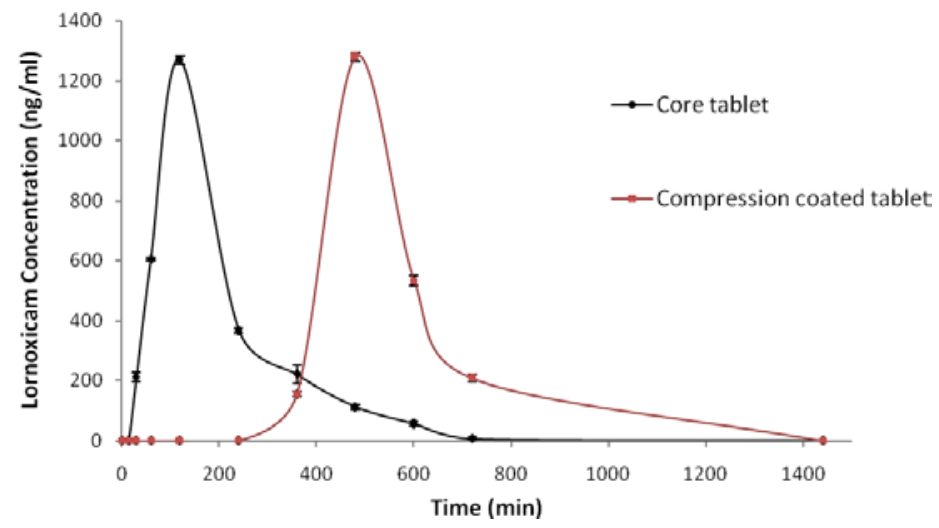

Fig. 7: Plasma drug concentration-time curves for pharmacokinetic study in rabbits, ${ }^{*}$ All points are presented as mean \pm SD of observations (n=3) 


\section{CONCLUSION}

A rapid and selective LC-MS/MS method was developed for the quantitative analysis of lornoxicam in rabbit plasma. An acceptable retention and separation of lornoxicam were obtained by using acetonitrile: $2 \mathrm{mmol}$ ammonium formate buffer $(70: 30 \mathrm{v} / \mathrm{v})$ as the mobile phase. The developed method was found to be highly sensitive and suitable for the detection of lornoxicam in plasma in concentrations as low as $5 \mathrm{ng} / \mathrm{ml}$. The results of the pharmacokinetic studies indicated that drug release from compression coated tablet took place only after a lag time of $5 \mathrm{~h}$. Thus, drug release, consistent with requirements for chronopharmaceutical drug delivery, was achieved from the compression coated tablet. Thus the formulation can be considered as one of the promising tools for chronotherapeutic management of rheumatoid arthritis with improved patient compliance.

\section{ACKNOWLEDGMENT}

The authors would like to thank the analysts of Skanda Life Sciences Pvt. Ltd., Bengaluru for their assistance in carrying out LC-MS/MS analysis.

\section{AUTHORS CONTRIBUTIONS}

All the author have contributed equally

\section{CONFLICT OF INTERESTS}

The authors declare that there are no conflicts of interest regarding the publication of this article.

\section{REFERENCES}

1. Bairy, Laxminarayana K. Chronotherapeutics: a hype or future of chronopharmacology. Indian J Pharmacol 2013;45:545-6.

2. Neeharika MS, Jeevana Jyothi B. Chronotherapeutics: an optimizing approach to synchronize drug delivery with circadian rhythm. J Crit Rev 2015;2:31-40.

3. Vitasta Singh, Ashwini Deshpande. The emergence of time programmed drug delivery system: chronotherapy of cardiovascular diseases. Int J Pharm Pharm Sci 2014;6:56-60.

4. Rajyalakshmi K, Indira Muzib Y, Saisree CH. Chronotherapeutic delivery of diclofenac sodium using almond gum as a carrier for the treatment of rheumatoid arthritis. Asian J Pharm Clin Res 2014;7:144-9.

5. Songa Ambedkar Sunil, Meka Venkata Srikanth, Nali Sreenivasa Rao, Kolapalli Venkata Ramana Murthy. Chronotherapeutic drug delivery from indomethacin compression coated tablets for early morning pain associated with rheumatoid arthritis. Curr Drug Delivery 2013;10:109-21.
6. Hetal Patel, Sonia Pandey, Vihari Patel, Ritesh Shah, Sanjay Tiwari. Pulsatile release of ketoprofen from compression coated tablets using eudragit polymers. Int J Pharm Pharm Sci 2015;8:224-9.

7. Songa Ambedkar Sunil, Nali Sreenivasa Rao, Meka Venkata Srikanth, Michael Uwumagbe Uhumwangho, Kommana Srinivas Phani Kumar, Kolaplli Venkata Ramana Murthy. Development and evaluation of a chronotherapeutic drug delivery system of torsemide. Braz J Pharm Sci 2011;47:593600.

8. Amit Bhat, Chowdary KPR, Shobharani RH, Lakshmi Narasu. Pharmacokinetic studies of chronopharmaceutical, conventional and pure drug delivery system of theophylline by LC-MS/MS method. J Pharm Sci Res 2011;3:1070-6.

9. Sateesh Kumar Vemula, Radhika Katkum. Colon-specific double-compression coated colon-specific double-compression coated pulsatile tablets of ketorolac tromethamine: formulation development and pharmacokinetics. J Drug Delivery Sci Technol 2015;29:78-83.

10. Sateesh Kumar Vemula. Formulation and pharmacokinetics of colon-specific double-compression coated mini-tablets: chronopharmaceutical delivery of ketorolac tromethamine. Int J Pharm 2015;491:35-41.

11. Jing Liu, Liangke Zhang, Wenjing Hu, Rui Tian, Yongzhen Teng, Chengyuan Wang. Preparation of konjac glucomannanbased pulsatile capsule for colonic drug delivery system and its evaluation in vitro and in vivo. Carbohydr Polym 2012; 87:377-82.

12. Krishnaiah YSR. Pharmacokinetic evaluation of guar gumbased colon-targeted drug delivery systems of mebendazole in healthy volunteers. I Controlled Release 2003;88:95-103.

13. Sateesh Kumar Vemula, Vijaya Kumar Bontha. Colon targeted guar gum compression coated tablets of flurbiprofen: formulation, development, and pharmacokinetics. Bio Med Res Int 2013;287919:1-8.

14. Paget JE, Barnes JM. Toxicity tests. In: Laurence DR, Bacharach AL. editors. Evaluation of drug activities: Pharmacometrics. 1st ed. Cambridge, USA: Academic Press; 1964. p. 135-66.

15. Mahrous 0 Ahmed, Abdullah A Al-Badr. Lornoxicam. In: Harry Brittain. editor. Profiles of drug substances, excipients, and related methodology. 1st ed. Oxford: Elsevier Inc; 2011. p. 205-37.

16. Nalini Kanta Sahoo, Madhusmita Sahu, Podilapu Srinivasa Rao, Goutam Ghosh. Extraction and quantification of lornoxicam in human plasma by liquid chromatography-tandem mass spectrometry in positive ion mode. Asian J Chem 2014;26:2452-8 